Article

\title{
Scorpion-Venom-Derived Antimicrobial Peptide Css54 Exerts Potent Antimicrobial Activity by Disrupting Bacterial Membrane of Zoonotic Bacteria
}

\author{
Jonggwan Park ${ }^{1}$, Jun Hee $\mathrm{Oh}^{2}$, Hee Kyoung Kang ${ }^{2}$, Moon-Chang Choi ${ }^{2}$, Chang Ho Seo ${ }^{1}$ \\ and Yoonkyung Park ${ }^{2, *}$ \\ 1 Department of Bioinformatics, Kongju National University, Kongju 38065, Korea; \\ for_quality@naver.com (J.P.); chseo@kongju.ac.kr (C.H.S.) \\ 2 Department of Biomedical Science, Chosun University, Gwangju 61452, Korea; \\ toqkfqkekr2@naver.com (J.H.O.); mgenetics@daum.net (H.K.K.); choist777@gmail.com (M.-C.C.) \\ * Correspondence: y_k_park@chosun.ac.kr; Tel.: +82-62-230-6854; Fax: +82-62-225-6758
}

Received: 8 October 2020; Accepted: 18 November 2020; Published: 20 November 2020

\begin{abstract}
Antibiotic resistance is an important issue affecting humans and livestock. Antimicrobial peptides are promising alternatives to antibiotics. In this study, the antimicrobial peptide Css54, isolated from the venom of C. suffuses, was found to exhibit antimicrobial activity against bacteria such as Listeria monocytogenes, Streptococcus suis, Campylobacter jejuni, and Salmonella typhimurium that cause zoonotic diseases. Moreover, the cytotoxicity and hemolytic activity of Css54 was lower than that of melittin isolated from bee venom. Circular dichroism assays showed that Css54 has an $\alpha$-helix structure in an environment mimicking that of bacterial cell membranes. We examined the effect of Css54 on bacterial membranes using $N$-phenyl-1-naphthylamine, 3,3'-dipropylthiadicarbbocyanine iodides, SYTOX green, and propidium iodide. Our findings suggest that the Css54 peptide kills bacteria by disrupting the bacterial membrane. Moreover, Css54 exhibited antibiofilm activity against L. monocytogenes. Thus, Css54 may be useful as an alternative to antibiotics in humans and animal husbandry.
\end{abstract}

Keywords: antimicrobial peptide; venom; antibiotics; zoonosis disease; feed additive

\section{Introduction}

The development and emergence of multidrug-resistant bacteria are a serious crisis for humans and livestock worldwide [1]. Many countries have monitored antibiotic use to decrease antibiotic resistance [2]. Because of antibiotic-resistant infections, annual global deaths are expected to increase from 700,000 in 2014 to 10 million by 2050. Most antibiotics are used in animal husbandry to protect against infection, treat ill animals, and promote growth [3,4]. Antibiotic-resistant bacteria used in animal husbandry spread to humans in various ways, such as through food, contaminated water, and soil [5]. Zoonotic diseases are those transferred from animals to infect humans, threatening the life and health of people worldwide [6]. The World Health Organization (WHO) reports the number of diseases originating from contaminated food. The Interagency Food Safety Analytics Collaboration described Salmonella typhimurium and Listeria monocytogenes as priority foodborne pathogens [7]. Listeria monocytogenes and Salmonella typhimurium that originate in animals can cause bacterial diseases such as listeriosis and salmonellosis, which are major bacterial zoonosis diseases [8].

Listeria monocytogenes is a Gram-positive bacterium found in various environments such as water, soil, and extreme environments, including low and high temperatures, high salt concentrations, and a broad $\mathrm{pH}$ range. Listeria monocytogenes infects immunocompromised persons, pregnant women, and neonates, resulting in abortion, meningitis, and blood poisoning [9]. Salmonella typhimurium is a 
Gram-negative and zoonotic pathogenic bacterium. Salmonella typhimurium causes gastrointestinal diseases associated with morbidity and mortality rates. This bacterium negatively affects animal husbandry because it infects young animals, resulting in sepsis, vomiting, fever, and abortion. Many antibiotics are added to animal feed of animals used for food to prevent zoonotic diseases. This has increased the antibiotic resistance of bacteria and become a global issue [10]. Preventing and controlling zoonotic diseases is crucial for the development of the livestock industry and maintaining public health [11]. Thus, alternatives to antibiotics should be used to kill bacteria without inducing resistance.

Venoms produced by different species, such as scorpions, snakes, and spiders, are used as protection or to capture prey. Various peptides found in venom produced by scorpions have been reported to have broad-spectrum antimicrobial, anticancer, and anti-inflammatory activities [12,13]. Numerous scorpion venom antimicrobial peptides (AMPs) have been reported as various therapeutic agents because of their low resistance rate $[14,15]$. Therefore, venoms are an important source of biologically active molecules and potential therapeutic agents, including AMPs.

AMPs produced by various organisms function as effector molecules to defend against pathogen infection [16]. AMPs commonly comprise 12-50 amino acids and show antibiotic activities against bacteria, fungi, and yeast, as well as anti-inflammatory activities. AMPs possess a net positive charge property, enabling them to bind to the bacterial membrane through electrostatic and hydrophobic interactions and penetrate the bacterial membrane to induce bacterial lysis [17]. Antimicrobial mechanisms of AMPs against bacteria are largely divided into two groups. First, AMPs can disrupt the bacterial membrane. Second, AMPs can cross the bacterial membrane without causing disruption to act as intracellular components [18]. AMPs are also less prone to developing resistance than currently used antibiotics [19]. In a previous study, the novel antimicrobial peptide Css54, isolated from the venom of scorpion Centruroides suffusus, was studied for its antimicrobial activity against Escherichia coli and Staphylococcus aureus. Moreover, the synergistic effect of Css54 with commercial antibiotics against S. aureus was evaluated [20].

In this study, Css54 is tested for its antimicrobial activity against L. monocytogenes, S. typhimurium, Streptococcus suis, and Campylobacter jejuni, which cause zoonotic disease. We used melittin, an antimicrobial peptide found in bee venom. We confirmed that Css54 has an antimicrobial activity similar to melittin. We tested the cytotoxicity of Css54 against PK(15) cells and hemolytic activities using pig kidney and sheep blood, respectively. Moreover, we examined its antibiofilm activity against L. monocytogenes and confirmed that antibacterial activity was maintained at various salt concentrations, temperatures, and $\mathrm{pH}$ values. The mechanism of action of Css54 against L. monocytogenes and S. typhimurium was studied by examining outer membrane permeability, membrane depolarization, and integrity of the bacterial membrane after treatment with Css54. Our findings show that Css54 can be used as an alternative to antibiotics to treat bacterial zoonosis.

\section{Results}

\subsection{Peptide Structure and Characterization}

Css54 was isolated from C. suffusus venom. The amino acid sequence, molecular weight, and net charge of Css54 are listed in Table 1. Css54 consists of 25 amino acids. The net charge value and hydrophobicity were 5 and 0.532 , respectively. A wheel diagram and three-dimensional structure analysis showed that the hydrophobic and hydrophilic regions formed an $\alpha$-helix structure (Figure 1A,B). Css54 synthesis and molecular weights were confirmed by reversed-phase high-performance liquid chromatography (RP-HPLC) using a C18 column and matrix-assisted laser desorption ionization time-of-flight mass spectrometry (MALDI-TOF MS; Figure S1A,B). 
Table 1. Amino acid sequence and properties of Css54.

\begin{tabular}{|c|c|c|c|c|}
\hline Name & Sequence & Molecular Mass (Da) & Net Charge & $\mathbf{H}^{\mathbf{a}}$ \\
\hline Css54 & FFGSLLSLGSKLLPSVFKLFQRKKE-NH ${ }_{2}$ & 2869.5 & 5 & 0.451 \\
\hline
\end{tabular}

A

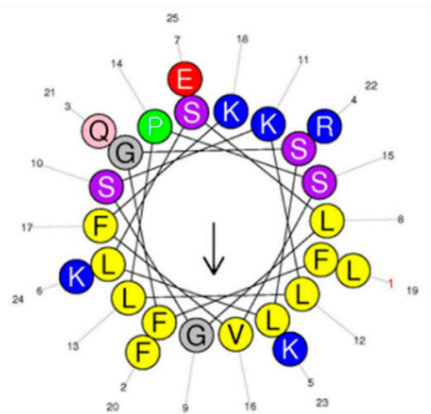

B

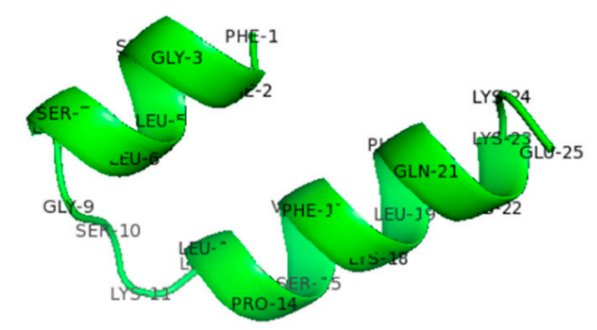

Figure 1. Structure analysis of Css54. (A) Helical wheel diagram of Css54 was obtained from the HeliQuest site (https://heliquest.ipmc.cnrs.fr/cgi-bin/ComputParams.py). (B) Three-dimensional structure of Css54 was predicted by PEP-FOLD3 and displayed by PyMOL.

\subsection{Circular Dichroism Measurements}

The secondary structure of Css54 was measured by circular dichroism (CD) spectroscopy in various concentrations of sodium dodecyl sulfate (SDS) to mimic the negative charge of the bacterial membrane and trifluoroethanol (TFE) solution to mimic the hydrophobic environment of the bacterial membrane [21,22]. In $10 \mathrm{mM}$ sodium phosphate, mimicking an aqueous environment, Css54 displayed a random coil (Figure 2A). In contrast, Css54 exhibited an $\alpha$-helix conformation in membrane-mimicking environments, depending on the TFE and SDS concentrations (Figure 2B,C). These results indicate that Css54 can affect the bacterial membrane through electrostatic and hydrophobic interactions.

A

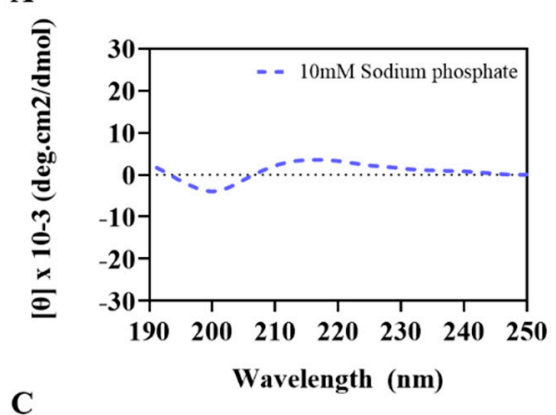

C

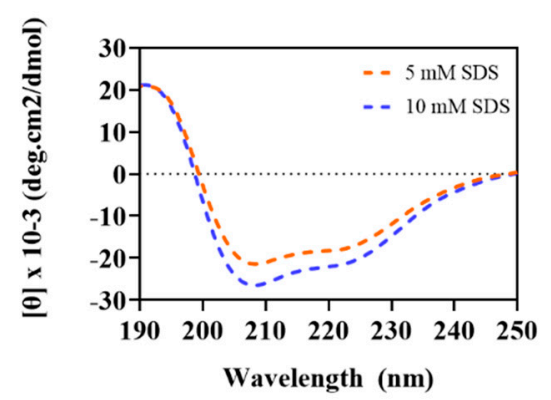

B

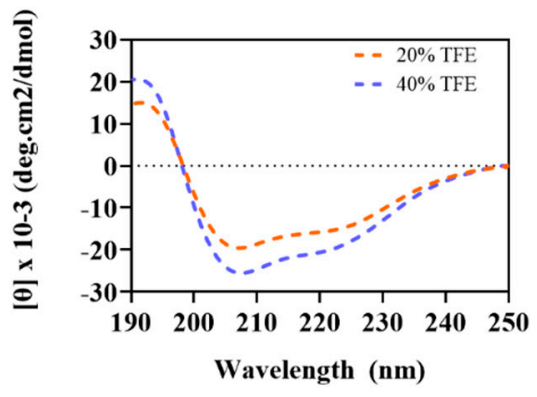

Figure 2. Circular dichroism (CD) spectra of Css54 measured in (A) $10 \mathrm{mM}$ sodium phosphate, (B) TFE at $20 \%$ and $40 \%$, and (C) SDS at 5 and $10 \mathrm{mM}$. Peptide concentration was fixed at $40 \mu \mathrm{M}$. 


\subsection{Antimicrobial Activities against Zoonotic Pathogens}

The antimicrobial activities of peptides and antibiotics against zoonotic pathogens are summarized in Table 2. We used melittin isolated from bee venom as a control, which is known as a lytic peptide with strong antibacterial activity and used in various antibiotics for animals. Css54 showed broad-spectrum antimicrobial activity against L. monocytogenes, S. typhimurium, Campylobacter jejuni, and Streptococcus suis, with minimum inhibitory concentrations (MICs) ranging from 2 to $4 \mu \mathrm{M}$. These MIC values are similar to those of melittin. The highest MIC values for cefotaxime, vancomycin, and colistin were more than $64 \mu \mathrm{M}$. These results suggest that Css 54 effectively inhibited zoonotic bacterial growth.

Table 2. Minimum inhibitory concentrations (MICs) of antimicrobial peptides and antibiotics against zoonosis bacteria.

\begin{tabular}{|c|c|c|c|c|c|c|}
\hline \multirow{2}{*}{ Strains } & \multicolumn{6}{|c|}{ MICs $(\mu \mathrm{M})$} \\
\hline & Css 54 & Melittin & Cefotaxime & Vancomycin & Colistin & Ampicillin \\
\hline \multicolumn{7}{|l|}{ Gram-positive (+) } \\
\hline $\begin{array}{c}\text { Listeria monocytogenes } \\
\text { (KCTC 3710) }\end{array}$ & 2 & 2 & 64 & 0.5 & 64 & 1 \\
\hline $\begin{array}{l}\text { Listeria monocytogenes } \\
\text { (KCCM 40307) }\end{array}$ & 2 & 1 & 4 & 0.5 & 32 & 0.5 \\
\hline $\begin{array}{l}\text { Listeria monocytogenes } \\
\quad(\text { KCCM 43155) }\end{array}$ & 2 & 1 & 4 & 0.5 & 16 & 1 \\
\hline $\begin{array}{l}\text { Streptococcus suis } \\
\text { (КСТС 3557) }\end{array}$ & 2 & 2 & $<0.13$ & $<0.13$ & $>64$ & 0.5 \\
\hline \multicolumn{7}{|l|}{ Gram-negative (-) } \\
\hline $\begin{array}{l}\text { Campylobacter jejuni } \\
\text { (КСТC 5327) }\end{array}$ & 2 & 2 & 32 & 0.5 & $>64$ & $>64$ \\
\hline $\begin{array}{l}\text { Salmonella typhimurium } \\
\text { (ATCC 14028) }\end{array}$ & 4 & 2 & 1 & 64 & 1 & 2 \\
\hline $\begin{array}{l}\text { Salmonella typhimurium } \\
\text { (CCARM 8009) }\end{array}$ & 4 & 2 & 0.5 & 64 & 2 & $>64$ \\
\hline $\begin{array}{l}\text { Salmonella typhimurium } \\
\text { (CCARM 8013) }\end{array}$ & 4 & 2 & 0.5 & 64 & 4 & $>64$ \\
\hline
\end{tabular}

\subsection{Cytotoxicity and Hemolytic Activities of Antimicrobial Peptides}

To measure the toxicity of Css54, we tested hemolytic activity by measuring hemoglobin, which appears red in the supernatant of sheep red blood cells (sRBCs) after treatment with the peptide. Melittin, which was used as a control, induced more than $80 \%$ hemolysis at $16 \mu \mathrm{M}$. However, the hemolytic percentage of Css54 was approximately $40 \%$ at $16 \mu \mathrm{M}$ (Figure 3A). To investigate the cytotoxicity of AMPs against mammalian cells, we performed an MTT assay. Css54 exhibited lower cytotoxicity than melittin at a concentration of $2.5 \mu \mathrm{M}$; melittin treatment resulted in cell survival rates of approximately $10 \%$. Css54 displayed a cell viability rate of approximately $50 \%$ at $8 \mu \mathrm{M}$. These results indicate that Css54 exhibited lower cytotoxicity than melittin (Figure 3B). 
A

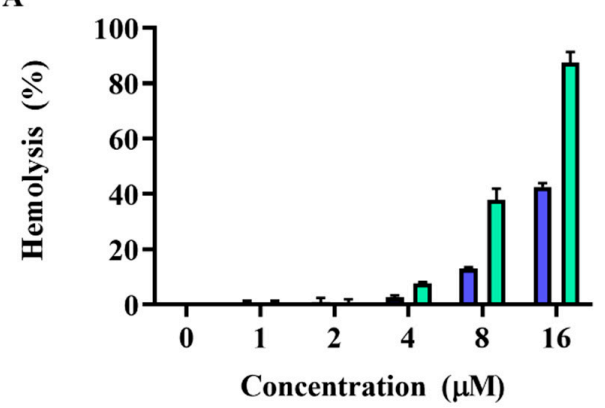

B

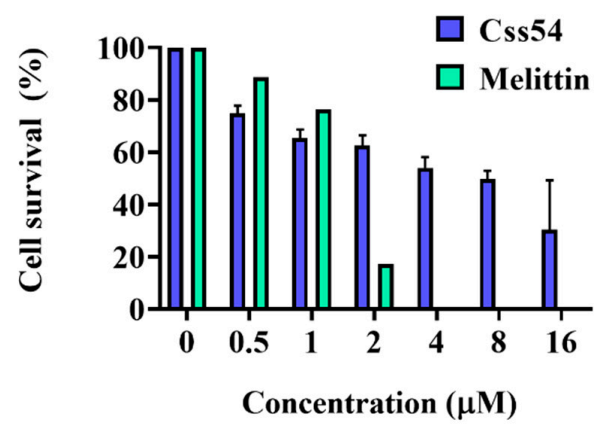

Figure 3. Hemolysis and cytotoxicity of antimicrobial peptides (AMPs). (A) Hemolytic activities were determined by measuring the release of hemoglobin from sRBCs at an absorbance wavelength of $414 \mathrm{~nm}$. Percentage of hemolysis in sheep RBCs incubated with peptides at increased concentrations. (B) Cytotoxicity assay of AMPs. PK(15) cells isolated from porcine kidney were treated with Css54, and melittin at different concentrations in DMEM supplemented 10\% FBS. Cell survival rates were measured by MTT assay.

\subsection{Antimicrobial Activities in Various Environments and Stability against Heat}

To assess the antimicrobial activity of Css54 under various L. monocytogenes growth conditions, Css54 was tested by MIC assay at $\mathrm{pH}$ values of $4,6,8$, and 10 , temperatures of $4-40{ }^{\circ} \mathrm{C}$, and salt concentrations of $0-8 \%$. At different $\mathrm{pH}$ values, Css54 at $0.5 \times$ and $1 \times$ MIC inhibited the growth of L. monocytogenes compared to the control (Figure 4A). Moreover, Css54 showed antimicrobial activity at various temperatures (Figure 4B). In the salt sensitivity test, the antimicrobial activity of Css54 was maintained in the presence of different salt concentrations (Figure 4C). Moreover, Css54 retained its antimicrobial activity after heating at $100{ }^{\circ} \mathrm{C}$ for $80 \mathrm{~min}$ (Figure $4 \mathrm{D}$ ). These results suggest that the antimicrobial activity of Css54 can be maintained under the growth conditions of $L$. monocytogenes and showed thermal stability for $80 \mathrm{~min}$.

A

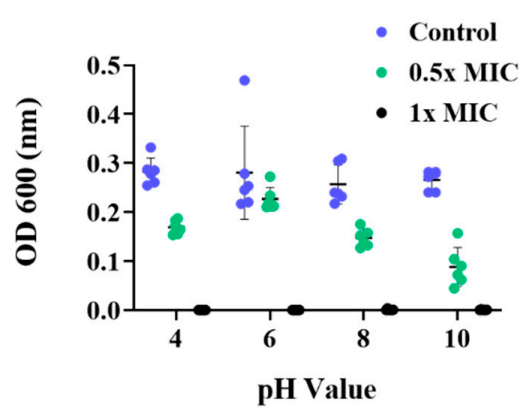

$\mathbf{C}$

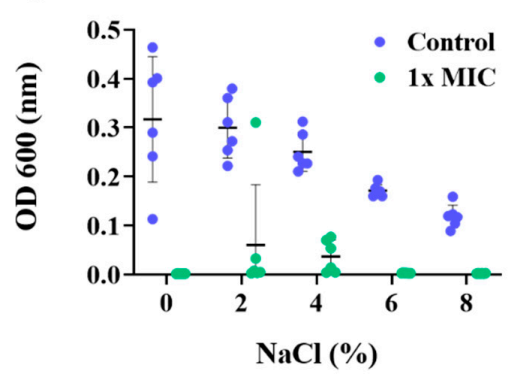

B

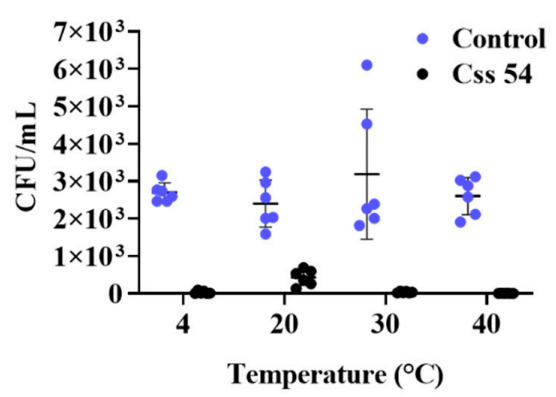

D

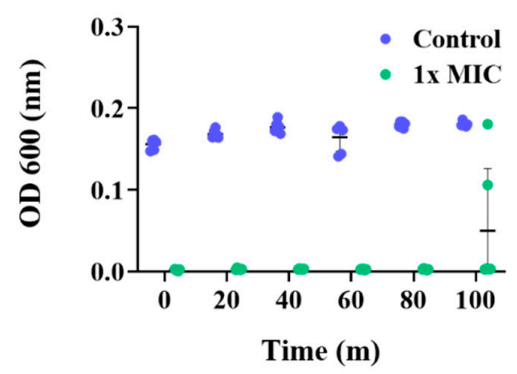

Figure 4. Antimicrobial activity of Css54 in different environments. (A) Effect of different pH values, (B) salt concentrations, and (C) temperatures on antimicrobial activity of Css54. (D) To evaluate thermal stability, Css54 at $1 \times$ MIC was incubated for 20, 40, 60, 80, and $100 \mathrm{~min}$ and then L. monocytogenes was added to the solution for incubation overnight at $37^{\circ} \mathrm{C}$. 


\subsection{Biofilm Inhibition Assay}

Listeria monocytogenes can attach to many food surfaces and form biofilms [23]. Therefore, the inhibition of biofilm formation by L. monocytogenes strains by Css 54 was assessed. The antibiofilm activities of Css54 and melittin were compared. Melittin is known to have antibiofilm activity [24,25]. Css54 and melittin (both at $4 \mu \mathrm{M}$ ) inhibited biofilm formation by L. monocytogenes (KCTC 3710) by more than 50\% (Figure 5A). For the strains L. monocytogenes (KCCM 43155) and L. monocytogenes (KCCM 40307), Css54 and melittin at $2 \mu \mathrm{M}$ inhibited biofilm formation by more than $50 \%$ (Figure $5 \mathrm{~B}, \mathrm{C}$ ).

A

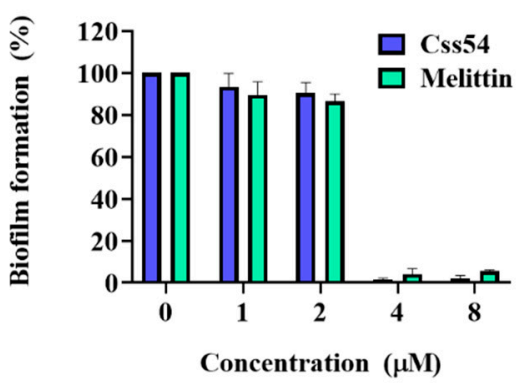

B

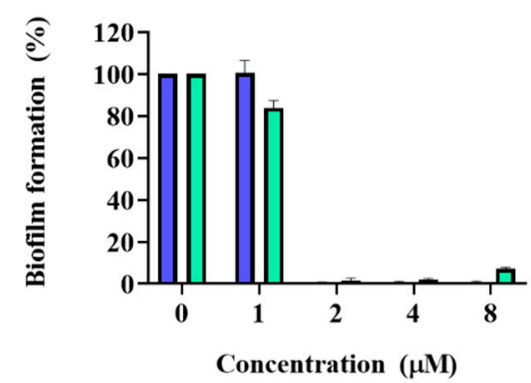

C

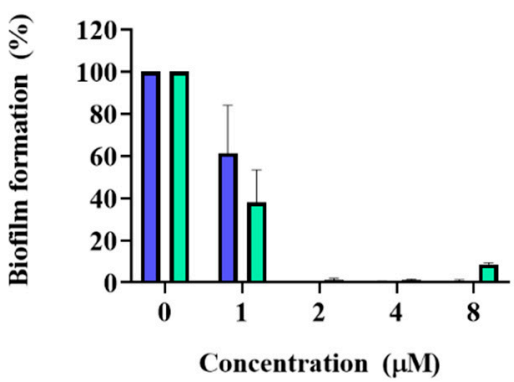

D
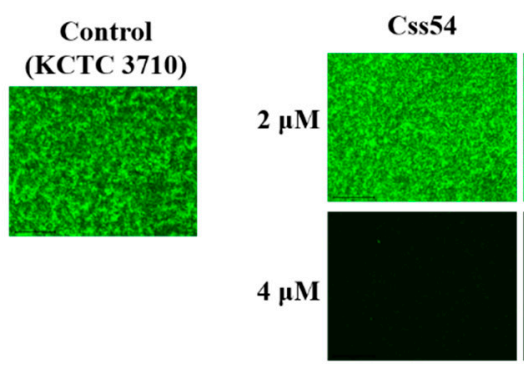

$\mathbf{E}$
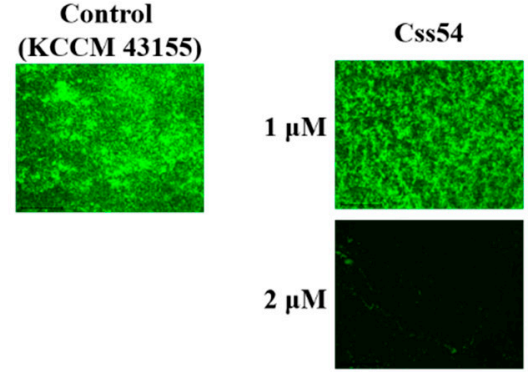

Melittin

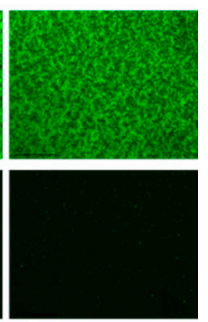

$\mathbf{F}$

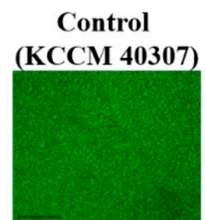

Melittin

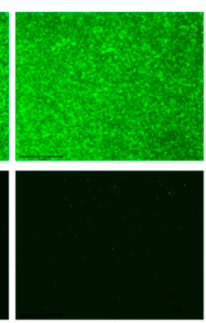

Melittin
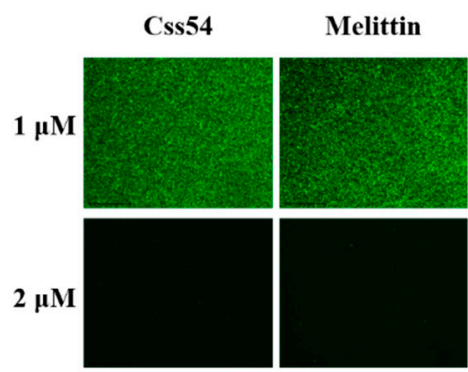

Figure 5. Inhibition of L. monocytogenes biofilm formation by Css54. (A) L. monocytogenes (KCTC 3710), (B) L. monocytogenes (KCCM 43155), and (C) L. monocytogenes (KCCM 40307) strains were mixed with AMPs for $24 \mathrm{~h}$. The mass of each biofilm was determined by crystal violet staining. Fluorescence microscopy image of biofilms formed by (D) L. monocytogenes (KCTC 3710), (E) L. monocytogenes (KCCM 43155), and (F) L. monocytogenes (KCCM 40307) strains after treatment with AMPs. Live bacteria were stained with SYTO9 dye and analyzed with an EVOS FL Auto 2 imaging system (Invitrogen).

To visualize bacteria in the biofilm, we used SYTO9, a green dye that stains live cells. After treatment with Css54 and melittin at 1,2, and $4 \mu \mathrm{M}$, L. monocytogenes (KCTC 3710), L. monocytogenes (KCCM 43155), and L. monocytogenes were viable within the biofilm (KCCM 40307), respectively, compared to the control (Figure 5D-F). These images were consistent with the quantitative measurement of biofilms by crystal violet staining and indicate that Css 54 has a strong antibiofilm activity, similar to melittin against $L$. monocytogenes. 


\subsection{Outer Membrane Permeability and Membrane Depolarization Assay}

We examined the disruption of the outer membrane of $S$. typhimurium after treatment with Css54 at $0.5 \times, 1 \times$, and $2 \times$ MIC in an N-phenyl-1-naphthylamine (NPN) uptake assay. NPN shows increased fluorescence intensity in hydrophobic environments [26]. The fluorescence intensity increased in a dose-dependent manner after treatment with Css54 (Figure 6A). These data suggest that the hydrophobic environment increased as the outer membranes were disrupted by Css54, resulting in an increase in fluorescence intensity.

A

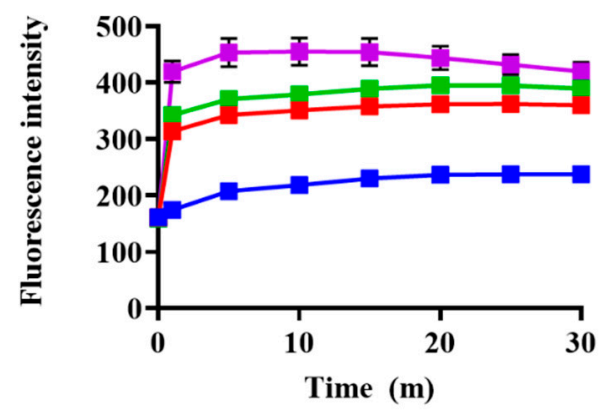

B

C
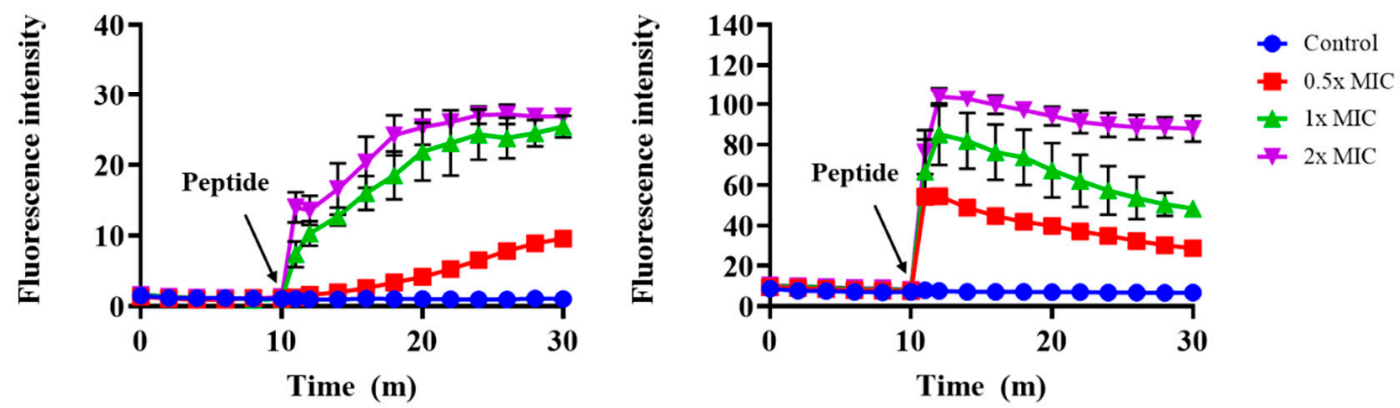

Figure 6. Outer membrane permeability and membrane depolarization assay. (A) S. typhimurium (ATCC 14028) outer membrane permeability induced by peptides. The outer membrane permeability of S. typhimurium induced by Css54 was measured using the fluorescent dye NPN (N-phenyl-1-naphthylamine. (B) S. typhimurium and (C) L. monocytogenes cytoplasmic membrane depolarization assay. Bacterial cytoplasmic membrane depolarization was analyzed using the potential-sensitive dye $\mathrm{DiSC}_{3}(5)$. Various concentrations of Css54 were added to the bacteria.

The effect of Css54 on membrane potential was investigated using $\mathrm{DiSC}_{3}(5) . \mathrm{DiSC}_{3}(5)$ is distributed in the cytoplasmic membrane of bacteria, where self-quenching occurs. When the bacterial membrane is damaged by antimicrobial agents, the dye is released into the medium, resulting in increased fluorescence intensity [27]. After completely stabilizing the fluorescence intensity of $\mathrm{DiSC}_{3}(5)$, L. monocytogenes and S. typhimurium were treated with Css54. In S. typhimurium, Css54 MIC showed a fluorescence intensity of approximately $30 \mathrm{~min}$ after $30 \mathrm{~min}$ (Figure 6B). In L. monocytogenes, Css54 at 2x MIC showed a fluorescence intensity of approximately 110 after 30 min (Figure 6C). The fluorescence intensity increased in a dose-dependent manner, indicating that Css54 induced membrane depolarization of $S$. typhimurium and L. monocytogenes.

\subsection{Effect of Peptides on Membrane Integrity}

The integrity of the bacterial membrane was determined using SYTOX green and propidium iodide (PI). Neither dye can pass through the intact membrane. However, if the bacterial membrane is disrupted by antimicrobial agents, these dyes bind to DNA, resulting in an increase in fluorescence 
intensity. Css54 at 0.5, 1, and $2 \times$ MIC at 30 min showed fluorescence intensities of approximately 31, 65, and 93 in S. typhimurium (Figure 7A). However, the control group of S. typhimurium showed a fluorescence intensity of approximately 4 . Css54 at $0.5,1$, and $2 \times$ MIC increased fluorescence intensity by approximately 17,23 , and 43 at $30 \mathrm{~min}$ in L. monocytogenes, whereas this value in the control group of L. monocytogenes was approximately 11 (Figure 7B). In S. typhimurium and L. monocytogenes, treatment with Css54 immediately increased the fluorescence intensity in a dose-dependent manner compared to the control sample in both strains.

A

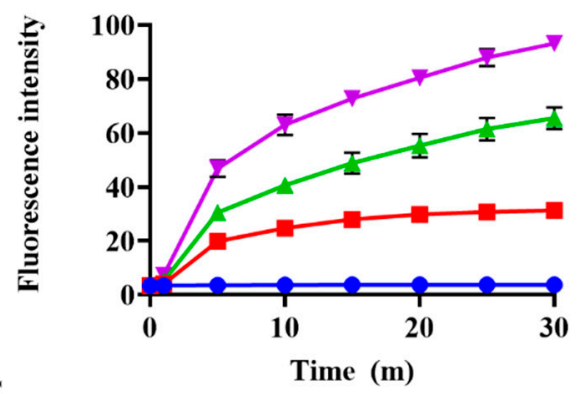

C

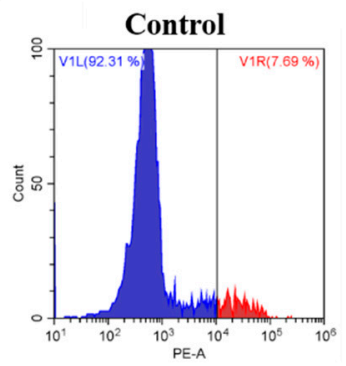

D

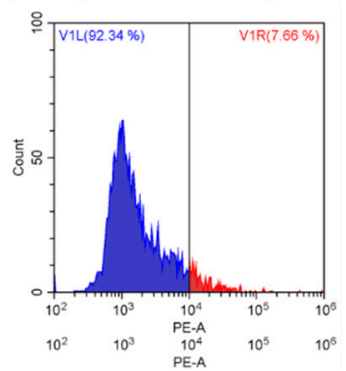

B

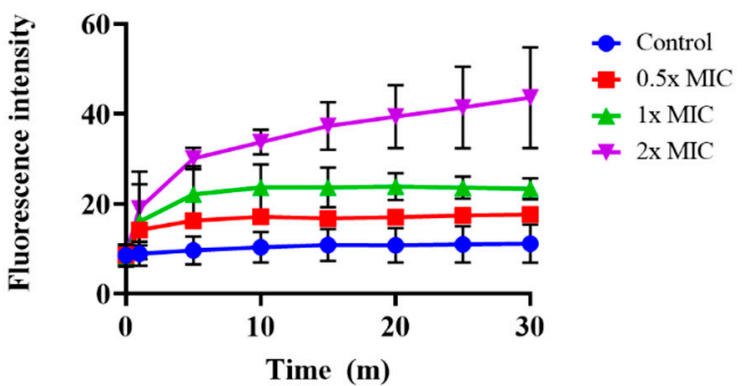

Time (m)
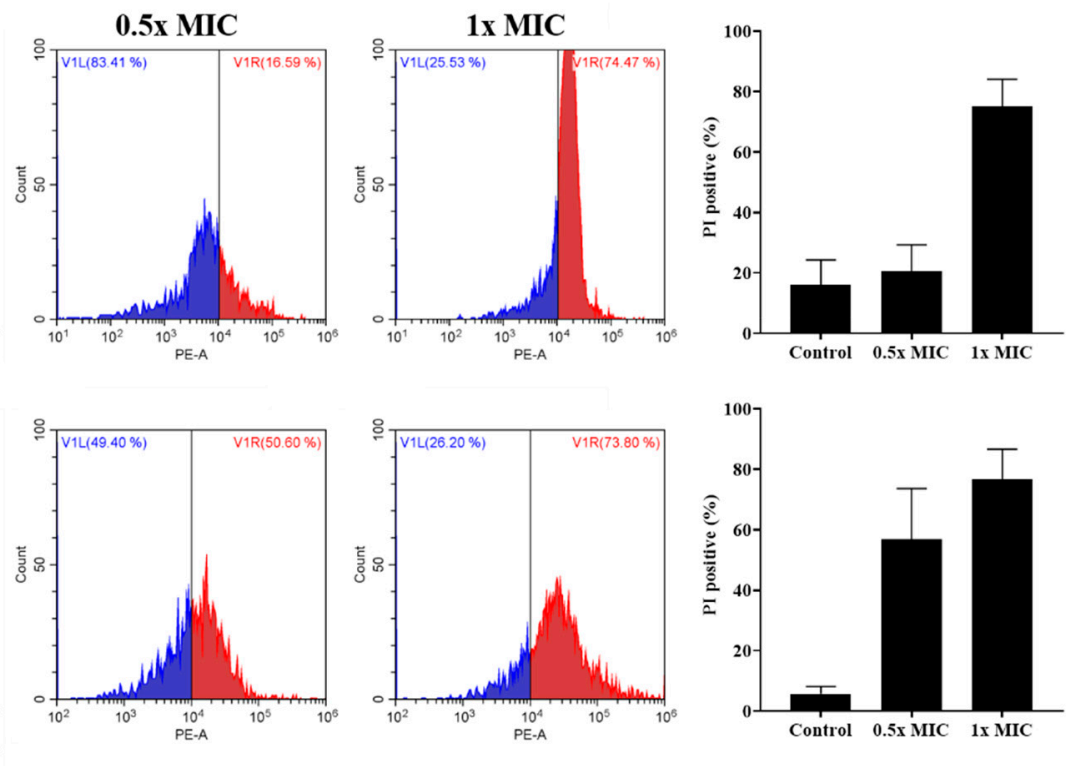

Figure 7. Analysis of L. monocytogenes and S. typhimurium membrane integrity after treatment with Css54. Css54 at $0.5 \times, 1 \times$, and $2 \times$ MIC were added to (A) S. typhimurium and (B) L. monocytogenes. Fluorescence intensity of SYTOX green was measured at emission and excitation wavelengths of 520 and $485 \mathrm{~nm}$, respectively. Flow cytometry analysis using propidium iodide staining against bacterial membrane integrity. Changes in (C) S. typhimurium and (D) L. monocytogenes after treatment with peptide at $0.5 \times$ and $1 \times$ MIC for $10 \mathrm{~min}$ were measured by flow cytometry using propidium iodide (PI).

We further analyzed the integrity of the bacterial membranes by PI staining and flow cytometry. In S. typhimurium, the percentage of PI staining was approximately $16 \%$ in the control group. After treatment with Css54 at $0.5 \times$ and $1 \times$ MIC, approximately $21 \%$ and $75 \%$ of bacteria were stained with PI (Figure 7C). In L. monocytogenes, the percentage of PI staining was approximately $6 \%$ in the control group. Following treatment with Css54 at $0.5 \times$ and $1 \times \mathrm{MIC}$, around $57 \%$ and $77 \%$ of bacteria were stained with PI (Figure 7D). Css54 dose-dependently induced an increase in PI-positive bacteria. Collectively, these data show that Css54 killed bacteria by disrupting the membranes of L. monocytogenes and S. typhimurium. 


\section{Discussion}

The overuse of antibiotics has rapidly increased the development of antibiotic-resistant bacteria and become a serious concern worldwide [28]. Many antibiotics are globally used on animals used as food, which is a major source of antibiotic-resistant bacteria development [29]. Thus, new antibacterial agents have been developed to kill antibiotic-resistant bacteria without causing resistance. AMPs have been considered as substitutes for antibiotics. AMPs play important roles as host defense molecules against infection in all living organisms [30]. AMPs show broad-spectrum activity against many strains of Gram-positive and Gram-negative bacteria through different modes of action, such as membrane disruption and via the intracellular target model [31,32]. AMPs have been reported to be less likely to develop drug resistance and have an advantageous effect on nutrient sources and the gut microbiota in animals $[29,33]$. Therefore, AMPs are good alternatives to the antibiotics used in humans and animal husbandry.

Venoms of various species are beneficial sources of bioactive molecules, such as AMPs [14]. In this study, we used melittin isolated from bee venom as a control peptide, as it is a representative lytic peptide known to have strong antimicrobial activity [34,35]. In a previous study, Css54 isolated from C. suffusus showed antimicrobial activity and synergistic effects with rifampicin, which is used to treat tuberculosis. Moreover, Css54 displayed an $\alpha$-helical structure in 60\% TFE [20]. However, how Css54 kills bacteria and whether it has antimicrobial activity against other bacteria, except for $S$. aureus and E. coli, remains unclear. Therefore, we focused on the antimicrobial activity and mechanism of action of Css54 against bacterial pathogens in zoonosis.

Zoonotic diseases are caused by pathogens such as bacteria, fungi, and viruses that transmit between animals and humans [36]. The WHO report in 2015 warned of the number of diseases caused by food contaminated with pathogenic bacteria such as Salmonella sp., Listeria Sp., Campylobacter sp., and the Enterobacteriaceae family [37]. We examined the antimicrobial activity of Css54 against bacteria on the zoonosis announced by the WHO; S. suis is a zoonotic pathogen that is related to swine infection [38]. Antimicrobial assays showed that Css54 exhibited antimicrobial activity against four strains similar to melittin. Moreover, the antimicrobial activity of conventional antibiotics such as cefotaxime, vancomycin, colistin, and ampicillin was evaluated. Css 54 exerted antimicrobial activity with low MIC compared to antibiotics against some strains. In a previous study, treatment with melittin showed no adverse effects on stomach tissue, including its function, and melittin was confirmed to have a protective effect against gastric inflammation and antitumor effects in vivo [39-41]. These reports indicate that Css54 can be developed as an effective treatment because of its lower toxicity (versus melittin). We confirmed that hemolytic activity towards sRBCs and cytotoxicity against pig kidney cells PK(15) was lower than that of melittin. The MIC value of Css54 ranged from 2 to $4 \mu \mathrm{M}$, and hemolytic activity and cytotoxicity following treatment with $16 \mu \mathrm{M}$ Css54 (approximately 4-fold of the MIC value) were approximately $10 \%$ and $40 \%$, respectively. Therefore, Css54 has the potential for treating bacterial diseases in animals and humans.

Listeria monocytogenes can survive in various typical environments, such as food processing and preservation [42]. This species can grow over a wide $\mathrm{pH}$ range of 4.5-9.6 and a temperature range of $2-45{ }^{\circ} \mathrm{C}$. Moreover, L. monocytogenes can survive in a high-salt environment, with up to $10 \% \mathrm{NaCl}$ [43]. Thus, L. monocytogenes is frequently present in animal foods and can contaminate foods. In addition to the biofilm inhibitory effect of Css54, one of the requirements for food and feed additives is stability under these conditions. Interestingly, Css54 maintained antimicrobial activity over wide $\mathrm{pH}$, temperature, and $\mathrm{NaCl}$ ranges. Additionally, the processing of many foods and feeds involves a heating step, and thus antimicrobial agents must exhibit thermal stability [44]. Css54 showed antimicrobial activity after incubation for $80 \mathrm{~min}$ at $100{ }^{\circ} \mathrm{C}$. These data demonstrate the potential of Css54 in applications such as food and feed additives.

Biofilm is a self-produced matrix of extracellular polymeric substances produced by microorganisms. Biofilms are important for the growth and survival of bacteria under various conditions, including low temperature, high salt concentrations, and low $\mathrm{pH}$ [45]. Listeria monocytogenes 
is a problem in food safety because it can form biofilms upon contact with food surfaces and persist in food processing environments [23]. Therefore, food additives used in the food industry should have antibiofilm activity. Recently, food additives have gradually become one of the most important antimicrobial agents in the food industry. Our data showed that Css 54 can inhibit biofilm formation by L. monocytogenes, similar to melittin.

AMPs display secondary structures such as $\alpha$-helices, $\beta$-sheets, loop types, and mixed structures [46]. CD spectra were determined to analyze the secondary structure of the peptides. AMPs showed a random coil structure in aqueous solution and formed a secondary structure in membrane-mimicking environments. We evaluated the secondary structure of Css54 in aqueous solution as well as bacterial membrane-mimicking environments such as SDS and TFE solutions. Css54 formed a random coil in an aqueous solution. In contrast, Css54 has an $\alpha$-helix structure in SDS, which mimics the negatively charged bacterial membrane, and in TFE, which can help AMPs induce secondary structure and mimic the hydrophobic environment [47]. These results suggest that Css54 exerts its antimicrobial activity by interacting with the bacterial membrane.

To determine the antimicrobial mechanism, we examined the effect of Css 54 on bacterial membranes in an outer membrane permeability assay using NPN dye and a cytoplasmic membrane depolarization assay using $\mathrm{DiSC}_{3}(5)$; we also examined membrane integrity using SYTOX green and PI. Css54 significantly increased NPN fluorescence intensity and $\mathrm{DiSC}_{3}(5)$ fluorescence intensity. Our results demonstrate that Css54 disrupts the outer membrane of $S$. typhimurium and induces membrane depolarization of L. monocytogenes and S. typhimurium. We examined the integrity of the bacterial membrane after treatment with Css54 using SYTOX green, PI, and SYTOX green. Fluorescence intensity increased when Css54 was added to the bacteria. This result was confirmed by flow cytometry using PI. Treatment with Css54 increased the PI fluorescence intensity, indicating that the bacterial membrane was disrupted by Css54. Our data show that Css54 has antimicrobial activity and a mechanism similar to melittin, but with lower cytotoxicity than melittin.

\section{Materials and Methods}

\subsection{Materials}

Thiazolyl blue tetrazolium bromide (MTT), N-phenyl-1-naphthylamine (NPN), 3,3'dipropylthiadicarbocyanine iodide $\left(\mathrm{DiSC}_{3}(5)\right)$, SYTOX green, propidium iodide (PI), dimethyl sulfoxide (DMSO), cefotaxime, colistin, and ampicillin were purchased from Sigma-Aldrich (St. Louis, MO, USA). Vancomycin was purchased from LPS Solution (Deajeon, Korea). Sheep red blood cells (sRBCs) were purchased from MB Cell (Seoul, Korea).

\subsection{Microorganisms}

Salmonella typhimurium (ATCC 14028) was purchased from the American Type Culture Collection (ATCC, Manassas, VA, USA). Listeria monocytogenes (KCTC 3710), Streptococcus suis (KCTC3557), and Campylobacter jejuni (KCTC 5327) were purchased from the Korea Collection for Type Cultures. L. monocytogenes (KCCM 40307) and L. monocytogenes (KCCM 43155) were purchased from the Korean Culture Center of Microorganisms (KCCM, Seoul, Korea). Salmonella typhimurium (CCARM 8009) and S. typhimurium (CCARM 8013) were purchased from the Culture Collection of Antibiotics Resistant Microbes (CCARM, Seoul, Korea). PK(15) isolated from porcine kidney was purchased from the Korean Cell Line Bank (Seoul, Korea).

\subsection{Peptide Synthesis and Sequence Analysis}

Peptides were synthesized using the solid-phase-9-fluorenylmethocycarbonyl1 (F-moc) method on a Rink amide-4-methylbenzhydrylamine resin and a Liberty microwave peptide synthesizer (CEM Co., Matthews, NC, USA). Hydroxybenzotriazole $(0.1 \mathrm{M})$ dissolved in piperidine and dimethylformamide and 0.45 M 2-(1H-benzotriazole-1-yil)-1,1,3,3-tetramethyluroniunm hexafluorophosphate dissolved in 
dimethylformamide were used as linkage reagents. After washing with dichloromethane, cleavage was performed in a solution of trifluoroacetic acid, phenol, water, and triisopropylsilane for $2 \mathrm{~h}$ at $25^{\circ} \mathrm{C}$. The crude peptides were diluted with ice-cold ether for precipitation. The peptides were added to tubes and then completely dried. The dried peptides were diluted in distilled water and then purified by RP-HPLC on a Jupiter C18 column $(4.6 \times 250 \mathrm{~mm}, 300 \AA, 5 \mu \mathrm{m}$; Phenomenex, Torrance, CA, USA). The molecular weights of the peptides were confirmed by MALDI-TOF MS (Kratos Analytical, Inc., Chestnut Ridge, NY, USA). Projections of the predicted three-dimensional structures were confirmed using PEP-FOLD3 (https://bioserv.rpbs.univ-paris-diderot.fr/services/PEP-FOLD3/). PEP-FOLD3 can be used for structural characterization of the peptides, followed by visualization using PyMOL [48,49]. The HeliQuest site (http://heliquest.ipmc.cnrs.fr) was used to generate helical wheel diagrams.

\subsection{Antimicrobial Activity Assay}

To investigate the antimicrobial activity of AMPs and antibiotics, the minimum inhibitory concentrations (MICs) of peptides and antibiotics were determined using the broth dilution method [50]. Listeria monocytogenes (KCTC 3710), L. monocytogenes (KCCM 40307), L. monocytogenes (KCCM 43155), and S. suis (KCTC 3557) were cultured overnight at $37^{\circ} \mathrm{C}$ in brain heart infusion (BHI). Salmonella typhimurium (KCTC 14028), S. typhimurium (CCARM 8009), S. typhimurium (CCARM 8013), and C. jejuni (KCTC 5327 were cultured overnight at $37^{\circ} \mathrm{C}$ in Mueller Hinton broth (MHB). These bacteria were diluted in appropriate media to a final concentration of $2 \times 10^{5} \mathrm{CFU} / \mathrm{mL}$. AMPs and antibiotics were diluted at concentrations of $0.5 .64 \mu \mathrm{M}$ in $10 \mathrm{mM}$ sodium phosphate buffer (Sp buffer, pH 7.2) in 96-well plates. Next, a $50-\mu \mathrm{L}$ aliquot of bacteria was added to $50 \mu \mathrm{L}$ of diluted peptide and antibiotics and incubated at $37^{\circ} \mathrm{C}$ for $16-24 \mathrm{~h}$. The growth of bacteria was measured as the absorbance at $600 \mathrm{~nm}$ using a microplate reader. MIC values were determined as the lowest concentration that inhibited bacterial growth compared to the control without AMPs and antibiotics.

\subsection{Hemolytic Activity}

The hemolytic activity of the peptides was determined using sRBCs. sRBCs were centrifuged at $2000 \times g$ for $10 \mathrm{~min}$ at $4{ }^{\circ} \mathrm{C}$ and washed three times with phosphate-buffered saline (PBS, pH 7.4). The washed sRBCs were diluted in PBS to a final concentration of $8 \%$. AMPs $(100 \mu \mathrm{L})$ were serially diluted from 1 to $16 \mu \mathrm{M}$ in 96-well plates, and then sRBCs were subsequently mixed for $1 \mathrm{~h}$ at $37^{\circ} \mathrm{C}$. The reacted samples in the 96 -well plate were centrifuged at $1500 \times g$ for $10 \mathrm{~min}$. The supernatant was transferred to a new 96-well plate, and the absorbance was measured at $414 \mathrm{~nm}\left(\mathrm{~A}_{414}\right)$. Next, $0.1 \%$ TritonX-100 and PBS were used as negative and positive controls, respectively. The percentage of hemolysis was calculated as follows [51]:

$$
\% \text { Hemolysis }=\left[\left(\mathrm{A}_{414} \text { in the peptides solution }-\mathrm{A}_{414} \text { in PBS }\right) /\left(\mathrm{A}_{414} \text { in } 0.1 \% \text { TritonX-100 }-\mathrm{A}_{414} \text { in PBS }\right)\right] \times 100
$$

\subsection{Cytotoxicity Activity}

The cytotoxicity of AMPs towards PK(15)-isolated porcine kidney cells was determined by MTT assay. PK(15) cells were cultured in Dulbecco's modified Eagle medium (DMEM) supplemented with $10 \%$ fetal bovine serum and $1 \%$ penicillin at $37{ }^{\circ} \mathrm{C}$ with $5 \% \mathrm{CO}_{2}$. The cells were seeded into 96 -well plates at $2 \times 10^{4}$ cells/well and incubated for $24 \mathrm{~h}$. AMPs were added to the wells at concentrations ranging from 0.5 to $16 \mu \mathrm{M}$ and incubated for $24 \mathrm{~h}$. Next, $20 \mu \mathrm{L}$ of $0.5 \mathrm{mg} / \mathrm{mL}$ MTT was added to the wells and incubated for $4 \mathrm{~h}$. The supernatant was removed, and $100 \mu \mathrm{L}$ DMSO was added to dissolve the formazan crystals. The absorbance was measured at $570 \mathrm{~nm}$ (A570) using a microplate reader. The positive control was incubated only with DMEM. The percent cell viability was calculated according to the following formula:

$$
\% \text { Cell viability }=\left(\mathrm{A}_{570} \text { in peptides solution } / \mathrm{A}_{570} \text { in positive control }\right) \times 100
$$




\subsection{Stability of Peptides}

The stability of Css54 was determined in different environments with varying $\mathrm{pH}$ values, temperatures, and salt concentrations. To confirm the effect of the antimicrobial activity of Css 54 at various $\mathrm{pH}$ values, $\mathrm{Sp}$ buffer was adjusted with $\mathrm{NaOH}$ and $\mathrm{HCl}$ to $\mathrm{pH}$ values of 4, 6, 8, and 10 . Css54 at $0.5 \times$ and $1 \times$ MIC was diluted in the prepared buffer and incubated with L. monocytogenes at $2 \times 10^{5} \mathrm{CFU} / \mathrm{mL}$ in BHI medium for $12 \mathrm{~h}$. The growth of L. monocytogenes was determined by measuring the absorbance at $600 \mathrm{~nm}$. To evaluate the stability of Css54 at various temperatures, L. monocytogenes at $2 \times 10^{5} \mathrm{CFU} / \mathrm{mL}$ in BHI medium was incubated with Css54 at $1 \times \mathrm{MIC}$ at 4, 20, 30, and $40{ }^{\circ} \mathrm{C}$ for $30 \mathrm{~min}$. The suspensions were plated on $\mathrm{BHI}$ agar plates. Colonies were counted after overnight incubation. To determine the effect of Css54 at various salt concentrations, L. monocytogenes at $2 \times 10^{5} \mathrm{CFU} / \mathrm{mL}$ in $\mathrm{BHI}$ medium supplemented with $2 \%, 4 \%, 6 \%$, and $8 \% \mathrm{NaCl}$ was incubated with Css54 at $1 \times \mathrm{MIC}$ overnight. The growth of L. monocytogenes was determined by measuring the absorbance at $600 \mathrm{~nm}$. To confirm heat resistance, Css54 at a final concentration of $1 \times$ MIC was incubated for different times $(20,40,60$, and $80 \mathrm{~min})$ at $100{ }^{\circ} \mathrm{C}$ and cooled on ice. Thereafter, L. monocytogenes at $2 \times 10^{5} \mathrm{CFU} / \mathrm{mL}$ was added to the suspension and incubated overnight. The growth of L. monocytogenes was determined by measuring the absorbance at $600 \mathrm{~nm}$.

\subsection{Biofilm Inhibition Assay}

To confirm biofilm inhibition by AMPs, L. monocytogenes was cultured in $\mathrm{BHI}$ at $37^{\circ} \mathrm{C}$. Bacterial suspensions at a final concentration of $5 \times 10^{5} \mathrm{CFU} / \mathrm{mL}$ were diluted in BHI supplemented with $0.2 \%$ glucose. Bacterial suspensions $(90 \mu \mathrm{L})$ and peptides $(10 \mu \mathrm{L})$ at concentrations of $1-8 \mu \mathrm{M}$ were mixed in a 96-well tissue culture plate. The mixture with bacteria and peptides was incubated for $24 \mathrm{~h}$ at $37^{\circ} \mathrm{C}$. After incubation, the supernatant was gently discarded, and the biofilms were fixed with $100 \%$ methanol for $10 \mathrm{~min}$. The methanol was discarded and dried. The dried biofilms were stained with $0.1 \%$ crystal violet for $10 \mathrm{~min}$ and then rinsed with distilled water until the BHI medium supplemented with $0.2 \%$ glucose appeared colorless. Finally, the stained biofilms were dissolved in $95 \%$ ethanol and measured at an absorbance of $595 \mathrm{~nm}\left(\mathrm{~A}_{595}\right)$. The percentage of biofilm mass was calculated using the following equation:

Biofilm mass $(\%)=\left(\mathrm{A}_{595}\right.$ of treated $\mathrm{AMPs} / \mathrm{A}_{595}$ of untreated biofilm $) \times 100$

\subsection{Circular Dichroism (CD) Spectroscopy}

The CD spectra of Css54 at $40 \mu \mathrm{M}$ were obtained in different buffers consisting of $10 \mathrm{mM}$ sodium phosphate, 5 and $10 \mathrm{mM}$ sodium dodecyl sulfate (SDS), and 20\% and 40\% 2,2,2-trifluoroethanol (TFE). CD spectra were measured using a Jasco 810 spectropolarimeter (Jasco, Tokyo, Japan) with a quartz cuvette (1.0-mm path length). The CD spectra were measured at wavelengths of 190-250 nm [52].

\subsection{Outer Membrane Permeability Assay}

Outer membrane permeability was measured using an NPN uptake assay. Salmonella typhimurium (ATCC 14028) was cultured in MHB medium. The bacteria were washed three times with 5 mM HEPES buffer ( $\mathrm{pH} 7.2$ ) and resuspended to an $\mathrm{OD}_{600}$ of 0.4 in $5 \mathrm{mM}$ HEPES buffer (pH7.2). The bacteria were placed in a black 96-well plate, and NPN at $10 \mu \mathrm{M}$ was added. Additionally, Css54 and melittin at $0.5 \times$, $1 \times$, and $2 \times$ MIC were added to each well. NPN fluorescence intensity was measured at excitation and emission wavelengths of 350 and $420 \mathrm{~nm}$, respectively, every $5 \mathrm{~min}$ for $30 \mathrm{~min}$.

\subsection{Membrane Depolarization Assay}

Membrane depolarization by the peptides in L. monocytogenes (KCTC 3710) and S. typhimurium (ATCC 14028) was measured using $\operatorname{DiSC}_{3}(5)$. Listeria monocytogenes (KCTC 3710) and Salmonella typhimurium (ATCC 14028) were cultured in BHI and MHB media, respectively. The bacteria 
were washed three times with $5 \mathrm{mM}$ HEPES buffer ( $\mathrm{pH}$ 7.2) supplemented with $20 \mathrm{mM}$ glucose. The bacteria were resuspended to an $\mathrm{OD}_{600}$ of 0.2 in 5 mM HEPES buffer ( $\mathrm{pH}$ 7.2) supplemented with $20 \mathrm{mM}$ glucose and $5 \mathrm{mM} \mathrm{KCl}$. $\mathrm{DiSC}_{3}(5)$ at $0.1 \mu \mathrm{M}$ was added and placed in a black 96-well plate. The mixture was incubated for $1 \mathrm{~h}$ to stabilize the fluorescence intensity. Css54 and melittin at $0.5 \times, 1 \times$, and $2 \times$ MIC were added to the mixture. The fluorescence intensity was measured at excitation and emission wavelengths of 622 and $670 \mathrm{~nm}$, respectively [53].

\subsection{SYTOX Green Uptake Assay}

Listeria monocytogenes (KCTC 3710) and Salmonella typhimurium (ATCC 14028) were cultured in $\mathrm{BHI}$ and MHB media, respectively. The bacteria were washed three times with $10 \mathrm{mM}$ Sp buffer ( $\mathrm{pH}$ 7.2). The bacteria were resuspended to a final concentration of $2 \times 10^{7} \mathrm{CFU} / \mathrm{mL}$ in $10 \mathrm{mM} \mathrm{Sp}$ buffer. The bacteria were incubated with $1 \mu \mathrm{M}$ SYTOX Green for $15 \mathrm{~min}$ in a black 96-well plate. Css54 and melittin at $0.5 \times, 1 \times$, and $2 \times$ MIC were added to the mixture. The fluorescence intensity was measured at excitation and emission wavelengths of 485 and $520 \mathrm{~nm}$, respectively [54].

\subsection{Flow Cytometry}

The integrity of the bacterial membranes was analyzed by flow cytometry. Listeria monocytogenes (KCTC 3710) and Salmonella typhimurium (ATCC 14028) were cultured in BHI and MHB media, respectively. The bacteria were washed three times with $10 \mathrm{mM} \mathrm{Sp}$ buffer and then resuspended to an $\mathrm{OD}_{600}$ of 0.4 in $10 \mathrm{mM}$ Sp buffer. The bacterial suspension was mixed with $2 \mu \mathrm{g} / \mathrm{mL}$ PI and incubated with Css54 at $0.5 \times$ and $1 \times$ MIC for $10 \mathrm{~min}$. The suspension was centrifuged and washed to remove unbound dye. The data were measured by CytoFLEX flow cytometry (Beckman Coulter, Brea, CA, USA) [55].

\section{Conclusions}

In conclusion, Css54 has antimicrobial activity against bacteria in zoonotic disease. Css54 showed lower cytotoxicity than melittin. Moreover, Css54 maintained antimicrobial activity under the growth conditions of L. monocytogenes and showed thermal stability. Css54 effectively inhibited biofilm formation by L. monocytogenes. Css54 displayed an $\alpha$-helix structure in bacterial membrane-mimicking environments. Css54 showed membrane lytic mechanisms similar to melittin. Our results suggest that Css54 can be used as an antibiotic and feed additive.

Supplementary Materials: The following are available online at http://www.mdpi.com/2079-6382/9/11/831/s1. Figure S1: RP-HPLC and mass spectrometry; (A) RP-HPLC profile on a C18 column with detection at $230 \mathrm{~nm}$; the black arrow represents the retention time of Css54 (25 min); (B) MALDI mass spectrometric analysis of Css54; the respective mass/charge ratio was 2869.5.

Author Contributions: Data curation, J.H.O. and H.K.K.; Formal analysis M.-C.C. and C.H.S. Supervision, Y.P.; Writing-orignial draft, J.P. All authors have read and agreed to the published version of the manuscript.

Funding: This work was supported by a National Research Foundation of Korea (NRF) grant funded by the Korean Government (No. 2019R1A2B5B03070330, NRF-2017M3A9E4077206) and an Institute for Information and Communications Technology Promotion (IITP) grant funded by the Korean government (MSIT; No. 2017-0-01714, Development of Antimicrobial Peptides using Deep Learning).

Conflicts of Interest: The authors declare no conflict of interest.

\section{References}

1. Veltri, D.; Kamath, U.; Shehu, A. Deep learning improves antimicrobial peptide recognition. Bioinformatics 2018, 34, 2740-2747. [CrossRef]

2. Xiao, Y.; Li, L. China's national plan to combat antimicrobial resistance. Lancet Infect. Dis. 2016, 16, 1216-1218. [CrossRef]

3. He, Y.; Yuan, Q.; Mathieu, J.; Stadler, L.; Senehi, N.; Sun, R.; Alvarez, P.J. Antibiotic resistance genes from livestock waste: Occurrence, dissemination, and treatment. Npj Clean Water 2020, 3, 1-11. [CrossRef] 
4. Van Boeckel, T.P.; Glennon, E.E.; Chen, D.; Gilbert, M.; Robinson, T.P.; Grenfell, B.T.; Levin, S.A.; Bonhoeffer, S.; Laxminarayan, R. Reducing antimicrobial use in food animals. Science 2017, 357, 1350-1352. [CrossRef]

5. Koch, B.J.; Hungate, B.A.; Price, L.B. Food-animal production and the spread of antibiotic resistance: The role of ecology. Front. Ecol. Environ. 2017, 15, 309-318. [CrossRef]

6. Karesh, W.B.; Dobson, A.; Lloyd-Smith, J.O.; Lubroth, J.; Dixon, M.A.; Bennett, M.; Aldrich, S.; Harrington, T.; Formenty, P.; Loh, E.H. Ecology of zoonoses: Natural and unnatural histories. Lancet 2012, 380, 1936-1945. [CrossRef]

7. Collaboration, A. Interagency Food Safety Analytics Collaboration (Ifsac) Strategic Plan Calendar Year 2017-2021. Available online: https://www.cdc.gov/foodsafety/pdfs/IFSAC-Strategic-Plan-2017-2021.pdf (accessed on 8 October 2020).

8. Chlebicz, A.; Śliżewska, K. Campylobacteriosis, salmonellosis, yersiniosis, and listeriosis as zoonotic foodborne diseases: A review. Int. J. Environ. Res. Public Health 2018, 15, 863. [CrossRef]

9. Farber, J.; Peterkin, P. Listeria monocytogenes, a food-borne pathogen. Microbiol. Mol. Biol. Rev. 1991, 55, 476-511. [CrossRef]

10. Garcia-Migura, L.; Hendriksen, R.S.; Fraile, L.; Aarestrup, F.M. Antimicrobial resistance of zoonotic and commensal bacteria in europe: The missing link between consumption and resistance in veterinary medicine. Vet. Microbiol. 2014, 170, 1-9. [CrossRef]

11. Rath, E.C.; Gill, H.; Bai, Y. Identification of potential antimicrobials against salmonella typhimurium and listeria monocytogenes using quantitative structure-activity relation modeling. PLoS ONE 2017, 12, e0189580. [CrossRef]

12. Liu, G.; Yang, F.; Li, F.; Li, Z.; Lang, Y.; Shen, B.; Wu, Y.; Li, W.; Harrison, P.L.; Strong, P.N. Therapeutic potential of a scorpion venom-derived antimicrobial peptide and its homologs against antibiotic-resistant gram-positive bacteria. Front. Microbiol. 2018, 9, 1159. [CrossRef]

13. Attarde, S.; Pandit, S. Scorpion venom as therapeutic agent-current perspective. Int. J. Curr. Pharm. Res. 2016, 7, 59-72.

14. Harrison, P.L.; Abdel-Rahman, M.A.; Miller, K.; Strong, P.N. Antimicrobial peptides from scorpion venoms. Toxicon 2014, 88, 115-137. [CrossRef]

15. Tossi, A.; Sandri, L.; Giangaspero, A. Amphipathic, $\alpha$-helical antimicrobial peptides. Pept. Sci. 2000, 55, 4-30. [CrossRef]

16. Kuroda, K.; Caputo, G.A. Antimicrobial polymers as synthetic mimics of host-defense peptides. Wiley Interdiscip. Rev. Nanomed. Nanobiotechnol. 2013, 5, 49-66. [CrossRef]

17. Zasloff, M. Antimicrobial peptides of multicellular organisms. Nature 2002, 415, 389-395. [CrossRef]

18. Kang, H.-K.; Kim, C.; Seo, C.H.; Park, Y. The therapeutic applications of antimicrobial peptides (amps): A patent review. J. Microbiol. 2017, 55, 1-12. [CrossRef]

19. Kumar, S.; Varela, M.F. Molecular mechanisms of bacterial resistance to antimicrobial agents. Chemotherapy 2013, 14, 522-534.

20. Garcia, F.; Villegas, E.; Espino-Solis, G.P.; Rodriguez, A.; Paniagua-Solis, J.F.; Sandoval-Lopez, G.; Possani, L.D.; Corzo, G. Antimicrobial peptides from arachnid venoms and their microbicidal activity in the presence of commercial antibiotics. J. Antibiot. 2013, 66, 3-10. [CrossRef]

21. Ma, Z.; Wei, D.; Yan, P.; Zhu, X.; Shan, A.; Bi, Z. Characterization of cell selectivity, physiological stability and endotoxin neutralization capabilities of $\alpha$-helix-based peptide amphiphiles. Biomaterials 2015, 52, 517-530. [CrossRef]

22. Chung, E.M.; Dean, S.N.; Propst, C.N.; Bishop, B.M.; van Hoek, M.L. Komodo dragon-inspired synthetic peptide drgn-1 promotes wound-healing of a mixed-biofilm infected wound. npj Biofilms Microbiomes 2017, 3, 1-13. [CrossRef]

23. Colagiorgi, A.; Bruini, I.; Di Ciccio, P.A.; Zanardi, E.; Ghidini, S.; Ianieri, A. Listeria monocytogenes biofilms in the wonderland of food industry. Pathogens 2017, 6, 41. [CrossRef]

24. Dosler, S.; Karaaslan, E. Inhibition and destruction of pseudomonas aeruginosa biofilms by antibiotics and antimicrobial peptides. Peptides 2014, 62, 32-37. [CrossRef] [PubMed]

25. Picoli, T.; Peter, C.M.; Zani, J.L.; Waller, S.B.; Lopes, M.G.; Boesche, K.N.; de Oliveira Hübner, S.; Fischer, G. Melittin and its potential in the destruction and inhibition of the biofilm formation by staphylococcus aureus, escherichia coli and pseudomonas aeruginosa isolated from bovine milk. Microb. Pathog. 2017, 112, 57-62. [CrossRef] 
26. Sun, S.; Zhao, G.; Huang, Y.; Cai, M.; Yan, Q.; Wang, H.; Chen, Y. Enantiomeric effect of d-amino acid substitution on the mechanism of action of $\alpha$-helical membrane-active peptides. Int. J. Mol. Sci. 2018, $19,67$. [CrossRef]

27. Sun, Y.; Dong, W.; Sun, L.; Ma, L.; Shang, D. Insights into the membrane interaction mechanism and antibacterial properties of chensinin-1b. Biomaterials 2015, 37, 299-311. [CrossRef]

28. Ventola, C.L. The antibiotic resistance crisis: Part 1: Causes and threats. Pharm. Ther. 2015, 40, $277-283$.

29. Van Boeckel, T.P.; Brower, C.; Gilbert, M.; Grenfell, B.T.; Levin, S.A.; Robinson, T.P.; Teillant, A.; Laxminarayan, R. Global trends in antimicrobial use in food animals. Proc. Natl. Acad. Sci. USA 2015, 112, 5649-5654. [CrossRef]

30. Mahlapuu, M.; Håkansson, J.; Ringstad, L.; Björn, C. Antimicrobial peptides: An emerging category of therapeutic agents. Front. Cell. Infect. Microbiol. 2016, 6, 194. [CrossRef]

31. Le, C.-F.; Fang, C.-M.; Sekaran, S.D. Intracellular targeting mechanisms by antimicrobial peptides. Antimicrob. Agents Chemother. 2017, 61. [CrossRef]

32. Pfalzgraff, A.; Brandenburg, K.; Weindl, G. Antimicrobial peptides and their therapeutic potential for bacterial skin infections and wounds. Front. Pharmacol. 2018, 9, 281. [CrossRef] [PubMed]

33. Sato, H.; Feix, J.B. Peptide-membrane interactions and mechanisms of membrane destruction by amphipathic $\alpha$-helical antimicrobial peptides. Biochim. Biophys. Acta (BBA) Biomembr. 2006, 1758, 1245-1256. [CrossRef] [PubMed]

34. Leveritt, J.M., III; Pino-Angeles, A.; Lazaridis, T. The structure of a melittin-stabilized pore. Biophys. J. 2015, 108, 2424-2426. [CrossRef] [PubMed]

35. Dempsey, C.E. The actions of melittin on membranes. Biochim. Biophys. Acta (BBA) Rev. Biomembr. 1990, 1031, 143-161. [CrossRef]

36. Oruko, R.O.; Odiyo, J.O.; Edokpayi, J.N. The role of leather microbes in human health. In Role of Microbes in Human Health and Diseases; IntechOpen: Rijeka, Croatia, 2019. [CrossRef]

37. World Health Organization. WHO Estimates of the Global Burden of Foodborne Diseases: Foodborne Disease Burden Epidemiology Reference Group 2007-2015; World Health Organization: Geneva, Switzerland, 2015.

38. Segura, M. Streptococcus suis research: Progress and Challenges. Pathogenes 2020, 9, 707. [CrossRef]

39. Abu-Zinadah, O.; Rahmy, T.; Alahmari, A.; Abdu, F. Effect of melittin on mice stomach. Saudi J. Biol. Sci. 2014, 21, 99-108. [CrossRef]

40. Rahmy, T.; Alahmari, A.; Abdu, F.; Abu-Zinadah, O. Protective effect of melittin against gastric inflammation in mice. Life Sci. J. 2013, 10, 1369-1384.

41. Duffy, C.; Sorolla, A.; Wang, E.; Golden, E.; Woodward, E.; Davern, K.; Ho, D.; Johnstone, E.; Pfleger, K.; Redfern, A. Honeybee venom and melittin suppress growth factor receptor activation in her2-enriched and triple-negative breast cancer. NPJ Precis. Oncol. 2020, 4, 1-16. [CrossRef]

42. Russo, P.; Hadjilouka, A.; Beneduce, L.; Capozzi, V.; Paramithiotis, S.; Drosinos, E.H.; Spano, G. Effect of different conditions on listeria monocytogenes biofilm formation and removal. Czech J. Food Sci. 2018, 36, 208-214. [CrossRef]

43. Liu, D.; Lawrence, M.L.; Ainsworth, A.J.; Austin, F.W. Comparative assessment of acid, alkali and salt tolerance in listeria monocytogenes virulent and avirulent strains. FEMS Microbiol. Lett. 2005, 243, 373-378. [CrossRef]

44. Dong, N.; Chou, S.; Li, J.; Xue, C.; Li, X.; Cheng, B.; Shan, A.; Xu, L. Short symmetric-end antimicrobial peptides centered on $\beta$-turn amino acids unit improve selectivity and stability. Front. Microbiol. 2018, 9, 2832. [CrossRef] [PubMed]

45. Miao, X.; Liu, H.; Zheng, Y.; Guo, D.; Shi, C.; Xu, Y.; Xia, X. Inhibitory effect of tq on listeria monocytogenes atcc 19115 biofilm formation and virulence attributes critical for human infection. Front. Cell. Infect. Microbiol. 2019, 9, 304. [CrossRef] [PubMed]

46. Mojsoska, B.; Jenssen, H. Peptides and peptidomimetics for antimicrobial drug design. Pharmaceuticals 2015, 8, 366-415. [CrossRef] [PubMed]

47. Kim, E.Y.; Rajasekaran, G.; Shin, S.Y. Ll-37-derived short antimicrobial peptide kr-12-a5 and its d-amino acid substituted analogs with cell selectivity, anti-biofilm activity, synergistic effect with conventional antibiotics, and anti-inflammatory activity. Eur. J. Med. Chem. 2017, 136, 428-441. [CrossRef] [PubMed]

48. Lamiable, A.; Thévenet, P.; Rey, J.; Vavrusa, M.; Derreumaux, P.; Tufféry, P. Pep-fold3: Faster de novo structure prediction for linear peptides in solution and in complex. Nucleic Acids Res. 2016, 44, W449-W454. [CrossRef] 
49. Yuan, S.; Chan, H.S.; Hu, Z. Using pymol as a platform for computational drug design. Wiley Interdiscip. Rev. Comput. Mol. Sci. 2017, 7, e1298. [CrossRef]

50. Wiegand, I.; Hilpert, K.; Hancock, R.E. Agar and broth dilution methods to determine the minimal inhibitory concentration (mic) of antimicrobial substances. Nat. Protoc. 2008, 3, 163-175. [CrossRef] [PubMed]

51. Lee, J.-K.; Park, S.-C.; Hahm, K.-S.; Park, Y. Antimicrobial hpa3nt3 peptide analogs: Placement of aromatic rings and positive charges are key determinants for cell selectivity and mechanism of action. Biochim. Biophys. Acta (BBA) Biomembr. 2013, 1828, 443-454. [CrossRef] [PubMed]

52. Kim, M.K.; Kang, N.H.; Ko, S.J.; Park, J.; Park, E.; Shin, D.W.; Kim, S.H.; Lee, S.A.; Lee, J.I.; Lee, S.H. Antibacterial and antibiofilm activity and mode of action of magainin 2 against drug-resistant acinetobacter baumannii. Int. J. Mol. Sci. 2018, 19, 3041. [CrossRef]

53. Kim, J.-Y.; Park, S.-C.; Yoon, M.-Y.; Hahm, K.-S.; Park, Y. C-terminal amidation of pmap-23: Translocation to the inner membrane of gram-negative bacteria. Amino Acids 2011, 40, 183-195. [CrossRef]

54. Lee, J.-K.; Luchian, T.; Park, Y. New antimicrobial peptide kills drug-resistant pathogens without detectable resistance. Oncotarget 2018, 9, 15616-15634. [CrossRef] [PubMed]

55. Kwon, J.Y.; Kim, M.K.; Mereuta, L.; Seo, C.H.; Luchian, T.; Park, Y. Mechanism of action of antimicrobial peptide p5 truncations against pseudomonas aeruginosa and staphylococcus aureus. AMB Express 2019, 9, 122. [CrossRef] [PubMed]

Publisher's Note: MDPI stays neutral with regard to jurisdictional claims in published maps and institutional affiliations. 